\title{
EDUCAÇÃO FISCAL INTEGRADA AO ENSINO FUNDAMENTAL: UM ESTUDO DE CASO NO MUNICÍPIO DE CÁCERES-MT ${ }^{1}$
}

\author{
Pamela Gabriela Ramos ${ }^{2}$ \\ Joana Ancila Pessoa Forte ${ }^{3}$
}

\begin{abstract}
RESUMO
A educação fiscal surge como um desafio educacional contemporâneo de grande relevância, considerando sua abordagem sobre aspectos presentes na vida cotidiana dos educadores. A Educação Fiscal é um processo que visa à construção de uma consciência voltada ao exercício da cidadania, ela deve tratar da compreensão do que é o Estado, suas origens, seus propósitos e da importância do controle da sociedade sobre os gastos públicos. Diante deste contexto foi desenhado o objetivo da pesquisa, que analisou a contribuição da inserção da educação físcal integrada ao ensino fundamental. Trata-se de uma pesquisa qualitativa, caracterizado como um estudo exploratório e descritivo, onde foi realizada uma pesquisa ação, a análise dos achados foi feita por meio do método de análise de conteúdo proposta por Bardin (1977), com auxilio do software Atlas.ti.
\end{abstract}

Palavras-Chave: Educação Fiscal, Gestão Pública e Cidadania.

\section{INTRODUÇÃO}

A educação é considerada o mais importante instrumento de transformação social, o individuo constrói seu conhecimento a partir do processo educacional vivenciado. Emediato (1978) afirma que as escolas não estão cumprindo os princípios básicos norteadores de suas atividades, que são a vinculação entre a educação escolar, o trabalho e as práticas sociais, das diversas áreas de conhecimento existente, poucas são abordadas, e ainda assim, não trata de temas relevantes à formação do individuo como cidadão. Galvão (2011) ressalta ainda que o conhecimento é transformador, pois ele revoluciona o comportamento, a atitude em relação ao que ocorre no mundo em que se está incluído.

A Educação Fiscal tem como objetivo a formação de cidadãos conscientes do cumprimento do seu dever com relação às obrigações tributárias e do direito de cobrar a adequada destinação dos recursos provenientes dos tributos arrecadados pelo Estado. Nesse sentido, o presente trabalho tem como objetivo analisar quais as contribuições de um

\footnotetext{
${ }^{1}$ Artigo apresentado no Encontro Nacional de Estudantes de Ciências Contábeis (ENECIC).

2 Pós-Graduanda em Gestão Pública. Docente na Universidade do Estado de Mato Grosso. E -mail: pamela.tutoriauab@gmail.com.

${ }_{3}^{3}$ Mestre em Administração de Empresas pela Universidade de Fortaleza (UNIFOR), com ênfase em Marketing. Atualmente Professora na Universidade do Estado de Mato Grosso (UNEMAT). E-mail: joanaforte@ gmail.com. 
programa de educação fiscal para o ensino fundamental ao estímulo da participação e exercício da cidadania e desenvolvimento do pensamento crítico.

Para aplicação do projeto escolheu-se como objeto a Escola Estadual Dr. José Rodrigues Fontes localizada no município de Cáceres (MT), atuando na cidade há 20 anos, oferecendo ensino fundamental e a modalidade EJA (Educação de Jovens e Adultos), contando atualmente com 65 profissionais entre docentes e técnicos administrativos e 952 alunos, funcionando nos períodos matutino, vespertino e noturno.

Conforme Art. $1^{\circ} \S 1^{\circ}$ e $2^{\circ}$ da Lei de Diretrizes Básicas (LDB, 1996), a educação escolar deverá vincular-se ao mundo do trabalho e a prática social. Há 6 mil áreas do conhecimento, e apenas 10 são abordadas, lembrando que, essas disciplinas são as mesmas desde o século XIX, onde rotineiramente recebem o mesmo tipo de abordagem, sem atentar para a dinâmica evolutiva e as frequentes mudanças nas demandas oriundas da sociedade, nesse sentido é importante trabalhar as maneiras de como olhar o mundo (ESAF, 2009). Gadotti (2005, p.35) entende que:

[...] A educação e a sociedade têm uma relação dinâmica. A educação é dependente da sociedade e vice-versa. Sendo assim, ratifica a ideia de que a educação formal não representa um único fator de mudança para a sociedade, porém se esta mudança não pode acontecer apenas pela educação, não acontecerá também sem esta. Desta forma, é notório que a luta pela transformação social deve estender-se além dos muros das escolas, não deve limitar-se ao ambiente escolar.

A Constituição Federal (1988) atribui à educação básica a responsabilidade de formação para a cidadania, além da educação para o trabalho e a vida em geral. As diretrizes curriculares de Educação Básica e Superior orienta que, as práticas de ensino observem as diversidades culturais, regionais, artísticos entre outros, proporcionando aos membros do universo escolar, acesso a questões sobre a vida social e estímulos a uma consciência crítica, propiciando aos mesmos o exercício da cidadania.

Os Parâmetros Curriculares Nacionais - PCN para o ensino fundamental propõem para o trabalho escolar a abordagem de questões que norteiam a construção da cidadania e da democracia por meio de temas transversais, de forma a motivar o aluno e dar significado ao que e ensinado em sala de aula. O Programa Nacional de Educação Fiscal- PNEF (2009) ressalta que, é importante trabalhar as maneiras de olhar o mundo, a escola precisa estabelecer novos métodos de ensino e incentivo aos estudantes. 


\section{REVISÃO DE LITERATURA}

A educação fiscal é um processo que visa á construção de uma consciência voltada ao exercício da cidadania, em sentido stricto sensu conforme o PNEF (2009, p. 02):

[...] deve ser compreendida como a abordagem didático-pedagógica capaz de interpretar as vertentes financeiras da arrecadação e dos gastos públicos de modo a estimular o contribuinte a garantir a arrecadação e o acompanhamento de aplicação dos recursos arrecadados em benefício da sociedade, com justiça, transparência, honestidade e eficiência, minimizando o conflito de relação entre o cidadão contribuinte e o Estado arrecadador.

A educação fiscal solidifica o conhecimento necessário ao exercício da cidadania. Reforçado por Galvão (2011), a Educação Fiscal é a conscientização do cidadão em relação à relevância do tributo para o Estado a fim de que esse tenha condições de promover o bemestar social a todos, cumprindo assim a sua função social.

A Constituição Federal de 1988 trouxe um conjunto de dispositivos para possibilitar ao cidadão a participação na gestão da administração pública. Participação social conforme Grau et al (2005) constitui:

[...] condição basilar para a democratização do Estado e a instauração de uma nova governança. Todavia, esta é fácil de ser proposta e difícil de ser realizada, implicando, antes de tudo, na construção de um novo padrão relacional entre o Governo e os beneficiários de suas ações, os cidadãos e a comunidade.

Segundo Portinho (2012) a cidadania é exercida quando há de fato a participação do cidadão nas decisões tomadas pela máquina administrativa. Mas, por herança histórica e por questões culturais, a efetividade desta participação ainda se encontra acanhada diante das dificuldades impostas pelo poder público. "Alçada o fundamento constitucional do Estado, a cidadania representa muito mais do que a mera participação no processo eleitoral. Cidadão não é sinônimo de eleitor, mas de um indivíduo participante e controlador da atividade estatal."

De acordo com Carmo (2008) alguns pontos referentes à educação fiscal podem ser questionados: Quem é que precisa educar-se nessa modalidade? São os alunos de primeira infância, das séries iniciais do ensino fundamental? Das séries finais do ensino fundamental, 
ou são os alunos do ensino médio? Ou isso é assunto para o ensino superior? Será que os professores já compreendem a educação fiscal? Será que os pais de alunos conhecem educação fiscal? Ou será que todos precisam educar-se nessa modalidade?

Nessa linha, o PNEF (2009) diz-se que, o Programa Nacional planeja alcançar, preferencialmente, em âmbito nacional, "estudantes e profissionais da educação básica e servidores", estes devido à abordagem que se dá ao desenvolvimento teórico e prático acerca dos "direitos e deveres recíprocos na relação Estado-cidadão".

A aplicação do Programa Nacional é possível em todas as camadas da sociedade. O PNEF possui um módulo especifico para a educação fundamental e outro para o ensino médio, Silva (2011) verificou-se que a abordagem da educação para a cidadania fiscal nas escolas de ensino fundamental e médio pode contribuir para a conscientização dos alunos e demais integrantes da comunidade escolar acerca da importância dos tributos para o financiamento da ação governamental e da necessidade de acompanhamento pelo cidadão em relação à aplicação dos recursos públicos.

Sendo assim, Educação Fiscal é o processo de acionamento da capacidade intelectual do ser humano, para conhecer finanças públicas proporcionando lhe condições de entender, analisar e refletir sobre captação e aplicação de recursos públicos, e consequentemente sobre o exercício de direitos e deveres advindos desse conhecimento (LIMA, 2008).

A educação é um direito essencial e fundamental à formação do indivíduo, a escola deve proporcionar o acesso a diversas formas e metodologias de aprendizagens, contribuindo para o desenvolvimento de cidadãos críticos e atuantes na sociedade. É na educação básica que a urgência dos problemas está a exigir, imediatamente, um empenho técnico e político especial, (MELLO, 2000). Um ensino de qualidade busca formar cidadãos capazes de interferir criticamente na realidade para transformá-la. A lei no 9.394 (1996) - Diretrizes de Base da Educação Nacional, art. 22 do capitulo II, da Educação Básica versa em assegurar ao educando, a formação comum indispensável para o exercício da cidadania que é um dos eixos norteadores das políticas de desenvolvimento social do governo.

A inserção da Educação Fiscal no ensino fundamental é um passo que a escola dá na constituição de uma sociedade mais justa e solidária, propiciando a participação dos indivíduos nas decisões que envolvam os recursos públicos. Para Silva (2011) a educação fiscal representa um ganho para as escolas, para os professores e os alunos, pois permite, desde cedo, trabalhar o conceito e a prática global da cidadania com as crianças. O programa 
permite um maior conhecimento sobre os impostos, além de ensinar a cobrar o retorno em melhores políticas públicas.

\section{PROCEDIMENTOS METODOLÓGICOS}

Quanto ao problema, a pesquisa desse estudo é qualitativa, na medida em que visa desenvolver conhecimento sobre o tema, propondo-se, a analisar as contribuições do Programa de Educação Fiscal para o exercício da cidadania. Segundo Minayo (2008, p.21):

[...] a pesquisa qualitativa responde a questões muito particulares, ela se preocupa, nas ciências sociais, com um nível de realidade que não pode ser quantificado, ou seja, ela trabalha com o universo de significados, motivos, aspirações, crenças, valores e atitudes, o que corresponde a um espaço mais profundo das relações dos processos e dos fenômenos que não podem ser reduzidos à operacionalização de variáveis.

A pesquisa qualitativa costuma ser direcionada ao longo do seu desenvolvimento, além do que não enumera ou mede os eventos, seu foco de interesse é amplo e parte da obtenção de dados descritivos mediante contato direto e interativo do pesquisados com a situação objeto de estudo. Maanen (1979) diz que a pesquisa qualitativa vem reduzir a distância entre indicado e indicador, entre teoria e dados, entre contexto e ação. Ressaltando que a maioria das pesquisas qualitativas é realizada no local de origem dos dados.

O estudo caracteriza-se como exploratório, pois visa familiarizar-se com um assunto ainda pouco conhecido, Gil (2007) acrescenta que ao final o pesquisador terá mais conhecimento a cerca do assunto e estará apto a construir hipóteses.

O estudo foi desenvolvido sob a forma de pesquisa ação, sendo essa originária dos trabalhos de Kurt Lewin, por volta de 1946, num contexto de pós-guerra, dentro de uma abordagem de pesquisa experimental, de campo. Este tipo de pesquisa é definida por Engel (2012) como:

[...] um tipo de pesquisa participante engajada, em oposição à pesquisa tradicional, que é considerada como "independente", "não reativa" e "objetiva". Como o próprio nome já diz, a pesquisa-ação procura unir a pesquisa à ação ou prática, isto é, desenvolver o conhecimento e a compreensão como parte da prática. É, portanto, uma maneira de se fazer 
pesquisa em situações em que também se é uma pessoa da prática e se deseja melhorar a compreensão desta.

A pesquisa-ação surgiu da necessidade de acabar com a lacuna entre teoria e prática. Uma das características deste tipo de pesquisa é intervir na prática de modo inovador. Em síntese, a pesquisa-ação é usada para elaborar uma analise da realidade em que está envolvido.

Os dados foram analisados através de fundamentos da análise de conteúdo proposta por Bardin (1977). Conforme Moraes (1999) esta metodologia consiste em descrever e interpretar todo e qualquer conteúdo referente a documentos e textos, reinterpretar o conteúdo das mensagens e desenvolver a compreensão além do texto, isto é conseguir perceber o que se quer dizer nas entrelinhas. Já Bardin (2010, p.44) define a análise de conteúdo como sendo:

[...] um conjunto de técnicas de análise das comunicações que utiliza procedimentos sistemáticos e objetivos de descrição do conteúdo das mensagens. Essa metodologia beneficia o campo da investigação social por meio da interação entre teoria e prática. Com características e possibilidades próprias, esta metodologia rompe as barreiras de uma técnica de análise de dados. Ela permite obter informações aos sujeitos mais críticos nas suas diversas áreas de atuação.

A análise do conteúdo foi realizada com o apoio do software Atlas.ti. Lançado em 1993, o software consiste em uma ferramenta para a análise de dados qualitativos que pode facilitar o gerenciamento e a interpretação dos mesmos. Walter e Bach (2009, p. 06) explicam que:

O Atlas.ti pode ser empregado em diferentes tipos de pesquisa, pois é flexível, podendo ser adaptado conforme os dados, objetivos e estratégia da pesquisa. Contudo, é mais bem aproveitado em pesquisas qualitativas e subjetivas que sejam, no mínimo, um pouco estruturadas.

Segundo Queiroz e Cavalcante (2011) com este software é possível analisar e gerenciar diferentes tipos de documentos e instrumentos de coleta de dados, tais como: respostas às questões abertas de questionários, relatórios de observação, cartas, enfim todos os textos expressos na modalidade escrita, além de áudio (transcrição de entrevistas não estruturada, músicas, reuniões, palestras e outros), imagens (fotos, desenhos, pinturas, e 
outros) e vídeos (gravações de reportagens televisivas, de aulas, de filmes, e outros). Queiroz e Cavalcante (2011, p. 117) acrescentam:

O software Atlas Ti permite a descoberta de fenômenos complexos, os quais, possivelmente, não seriam detectáveis na simples leitura do texto, principalmente, em relação à técnica tradicional de tratamento dos dados manualmente, com a utilização de lápis, tesoura e cola, porque é possível integrar as unidades hermenêuticas (projetos primários) entre si.

O trabalho com este tipo de software apresenta vantagens como: flexibilidade, visto que seu uso pode ser adaptado para diferentes pesquisas, agilidade e facilidade nas etapas do processo, possuem ferramentas para o registro de todas as etapas da análise, o que facilita a comprovação empírica das interpretações e das alterações no decorrer do processo.

\section{APRESENTAÇÃO E DISCUSSÃO DOS RESULTADOS}

O primeiro passo para a coleta dos dados foi a apresentação do programa aos profissionais da escola, seguido do convite e apresentação aos alunos. A metodologia foi elaborada com base nos objetivos do PNEF adequado a realidade na qual o programa foi implantado. Ressalta-se que o alvo do projeto foram estudantes do ensino fundamental, especificamente do $9^{\circ}$ ano, sendo 26 alunos, com idade entre 13 e 16 anos.

As aulas foram realizadas aos sábados, da 13h00min às 16h30min. Como metodologia utilizavam-se textos, músicas, debates e atividades práticas pertinentes ao tema. Todo o cronograma foi planejado, elaborado plano de aula e realizadas observações sobre a realidade na qual os estudantes estão inseridos. As atividades trabalhadas em sua grande maioria foram registradas, em específico a I Feira de Educação Fiscal realizada com o objetivo de transmitir informações relevantes ao exercício da cidadania.

Os dados foram coletados a partir da observação direta e participativa. Este procedimento, introduzido pela Escola de Chicago por volta de 1920 e conforme ressalta Rifiotis (2007), o modelo representa uma ruptura com a tradição científica, em que apenas eram relatados os fatos, há uma significativa diferença entre relacionar-se esporadicamente com os sujeitos de pesquisa ou basear-se em informações coletadas por outros e estar efetiva e cotidianamente com eles, a observação participante busca interação entre pesquisadores e membros, esta consiste na primeira etapa do processo participativo da pesquisa. Conforme Queiroz e Cavalcante (2011, p.279) : 
[...] O processo de observação participante segue algumas etapas essenciais. $\mathrm{Na}$ primeira delas, há a aproximação do pesquisador ao grupo social em estudo. Esse é um trabalho longo e difícil, pois o observador precisa trabalhar com as expectativas do grupo, além de se preocupar em destruir alguns bloqueios, como a desconfiança e a reticência do grupo.

De acordo com Engel (2012) além da área educacional, a pesquisa-ação pode ser aplicada em qualquer ambiente de interação social que se caracterize por um problema, no qual estão envolvidos pessoas, tarefas e procedimentos. Engel (2012, p. 184) apresenta algumas características essenciais da pesquisa:

1. O processo de pesquisa deve tornar-se um processo de aprendizagem para todos os participantes e a separação entre sujeito e objeto de pesquisa deve ser superada.

2. O pesquisador parece-se, neste contexto, a um praticante social que intervém numa situação com o fim de verificar se um novo procedimento é eficaz ou não.

3. A pesquisa-ação é situacional: procura diagnosticar um problema específico numa situação também específica, com o fim de atingir uma relevância prática dos resultados.

4. A pesquisa-ação é auto avaliativa, isto é, as modificações introduzidas na prática são constantemente avaliadas no decorrer do processo de intervenção e o feedback obtido do monitoramento da prática é traduzido em modificações, mudanças de direção e redefinições, conforme necessário, trazendo benefícios para o próprio processo, isto é, para a prática, sem ter em vista, em primeira linha, o benefício de situações futuras.

5. A pesquisa-ação é cíclica: as fases finais são usadas para aprimorar os resultados das fases anteriores.

A segunda etapa consiste na observação dos fatos, documentos e registros dos acontecimentos, na terceira etapa são sistematizados e organizados os dados.

Dentro do contexto educação fiscal deve-se abordar as formas de como esta se faz presente na vida das pessoas, seja no presente ou futuro. $\mathrm{O}$ primeiro tema a ser trabalhado em sala de aula foi a educação fiscal em um contexto geral, onde o meio utilizado para atingir esse objetivo foi a dinâmica da árvore (Cantinho das Letras, 2012). Foi solicitado aos alunos que escrevessem três sonhos para analisarmos a relação deste com a educação fiscal. Quando se fala em sonho, pesquisas (Projeto Sonho Brasileiro) indicam que 55\% dos brasileiros respondem algo relacionado à formação profissional e emprego, os demais incluem casa própria, dinheiro, família, carro, viagens e independência financeira. 
Como resultado da dinâmica, os alunos trouxeram em suas falas assuntos relacionados à educação, emprego, renda, qualidade de vida, moradia e custo de vida, o que nos remete as abordagens da educação fiscal. Analisando os dados obtidos no programa ratifica-se o que é apresentado nas pesquisas, fortalecendo a necessidade da abordagem da educação fiscal e sua relação com a realidade na qual o estudante está inserido, correlacionando teoria a prática, pois os sonhos citados (teoria) quando concretizados (prática), levam diretamente á execução dos temas propostos dentro do programa de educação físcal; Direitos e Deveres.

Alguns temas em específico se destacaram ao aparecer diversas vezes nas citações dos estudantes, como a educação citada 13 vezes, cujo sonho recorrente é a formação em ensino superior. A relação educação x educação fiscal está no fato de que todo esse sistema é financiado com recursos oriundos da população, sendo o papel do programa orientar os meios de reivindicar o direito de acesso ao ensino de qualidade.

Diversas evocações apresentam o desejo de melhoria para a cidade e o acesso a rede de esgoto, iluminação pública, coleta de lixo entre outros, surge aqui a relação direito x dever, na qual o cidadão contribui, porém tem o direito usufruir de uma cidade melhor para se viver.

Para melhor fixação e entendimento do que era abordado em sala, houve diversos trabalhos com a utilização de música, que conforme os Parâmetros Curriculares Nacionais (PCN), essa prática dentro do processo de ensino tem por objetivo geral abrir espaço para que os alunos possam se expressar assim como promover experiências de apreciação e abordagem em seus vários contextos culturais e históricos. O professor ao trazer a músicas para sala de aula deve observar a relação da música em suas várias abordagens com o que está sendo trabalhado. No programa uma das músicas utilizadas foi "Até Quando" de Gabriel Pensador, justificado pelo fato de que há fortes criticas sociais e políticas em torno da música justamente pelo seu contexto em que instiga o individuo a tomar atitudes com relação a sua posição de comodidade dentro da realidade na qual está inserido. O objeto de análise no que refere-se a música foi o questionamento ao estudante sobre qual trecho da música mais se identificou.

O processo de identificação de trechos da música que mais chamou a atenção vai ter uma ligação direta com o que já foi trabalhado durante o programa. Alguns trechos foram mais citados, dentre eles o refrão:

“ATÉ QUANDO VOCÊ VAI LEVANDO PORRADA, PORRADA!!!! ATÉ QUANDO VOCÊ VAI FICAR FAZENDO NADA? ATÉ QUANDO VOCÊ VAI LEVANDO PORRADA, PORRADA!!!! ATÉ QUANDO VOCÊ VAI SER SACO DE PANCADA? 
O trecho acima é justificado pela necessidade de ação do cidadão para que assim propiciem a mudança que tanto desejam, observa-se a resposta de um aluno na qual diz o seguinte: "ao escutar a música ele cantava de uma forma que me despertou a vontade de usufruir meus direitos". Outro trecho várias vezes citado está relacionado com a corrupção, impunidade e violência como justificativa, indicando que esses assuntos por estarem mais presentes no cotidiano, na mídia e nos jornais são de fácil assimilação e produção de conceitos por parte dos alunos.

Visando expandir as informações do tema trabalhado com os alunos foi realizada uma feira de Educação Fiscal, aberta a comunidade, onde os alunos abordaram os temas inerentes ao projeto, como arrecadação, tributação, destinação dos recursos, meios de acompanhamento e fiscalização do dinheiro público, controle social e cidadania. Ao término da visita foi entregue um questionário cuja finalidade era uma avaliação da iniciativa. A primeira pergunta do questionário aplicado à população vem responder o objetivo geral da pesquisa, que é os benefícios que a iniciativa propicia aos alunos e a sociedade em modo geral. Unanimente todas as respostas foram positivas com relação à relevância da feira, tendo como principais justificativas o conhecimento que essa feira transmite, seguido da conscientização e senso crítico proporcionado aos participantes.

O programa nacional de Educação Fiscal elenca uma série de propostas a serem alcançadas, dentro delas está o que se alcançou com a I Feira de Educação Fiscal, que conforme citado em vários momentos incluem: o fortalecimento dos mecanismos de transformação social por meio da educação, neste caso foi disponibilizado a sociedade informações referentes ao tema (conhecimento), desenvolvimento da consciência crítica da sociedade e construção da consciência cidadã. Observa-se o fato de que as perguntas do questionário eram abertas, onde os visitantes colocavam sua opinião, que satisfatoriamente coincidiu com o que é proposto pelo PNEF, indicando o sucesso da abordagem do tema na cidade de Cáceres-MT.

A educação fiscal surge como proposta de despertar na sociedade uma reflexão e uma ação participativa. Filho (BRASIL, 2013) ressalta que:

É necessário que a população domine informações sobre a gestão fiscal do país, estado ou município. A educação fiscal propõe-se a disseminar conhecimentos que embasam essa atuação: como se arrecadam os recursos? como se investe o dinheiro? de que mecanismos a sociedade dispõe para controlar o destino de recursos e bens públicos? 
Quando questionados sobre os conhecimentos adquiridos na I Feira de Educação Fiscal a maior parte responderam que não tinham conhecimento a respeito dos impostos, seguido dos temas inerentes, na qual repetidamente aparece o tema pirataria, justificado pelo fato de que as informações relativas aos prejuízos (na área da saúde e financeira) geralmente não são divulgadas, ficando restritos somente a informações referentes à apreensão em termos de quantidade.

Essa pergunta foi feita com o objetivo primordial de saber quais temas abordados na feira que a população não tinha conhecimento, o resultado surpreendente demonstra que em $1^{\circ}$ lugar, apesar de ser uma palavra muito conhecida, pouco se discute a cerca dos impostos. Todas as suas abordagens dentro da feira em um momento ou outro foi citado como algo novo que o visitante aprendeu, como: as alíquotas de IR, os impostos no contexto geral, e o curioso fato de que o feijão-preto é importado.

Uma pesquisa Ibope encomendada pela Associação Comercial de São Paulo (ACSP, 2013) aponta que 90\% dos brasileiros gostariam de saber o quanto pagam de imposto, inclusive esse surge como o tema emergente no que refere-se a abordagem na feira de Educação Fiscal.

Outros temas também foram destacados, realçando a relevância de sua abordagem, confirmando a necessidade de um programa contínuo de educação físcal que possam transmitir essas informações a sociedade.

\section{CONCLUSÕES}

A pesquisa foi realizada visando responder os objetivos propostos, o primeiro momento refere-se à implantação do projeto de educação fiscal em uma escola, neste caso a Escola Estadual Dr. José Rodrigues Fontes, o que foi feito em março de 2012. Dentro de todo o contexto de realização do programa foi possível analisar a repercussão do programa para o desenvolvimento crítico dos alunos, comprovado o alcance do mesmo através de textos produzidos.

Como se trata de uma experiência nova não só no munícipio de Cáceres, assim como no Estado de Mato Grosso, fez-se necessário avaliar os aspectos positivos e as melhorias a serem realizadas no programa, o que foi alcançado através da análise dos conteúdos dos trabalhos, bem como a avaliação feita pela comunidade na I feira de Educação Fiscal. 
Os resultados da iniciativa formam a base para levantar elementos de defesa de um programa contínuo de educação fiscal integrada ao ensino fundamental, o que se justifica pelo fato do sucesso e dedicação dos alunos na abordagem e exposição do tema a sociedade.

Para o alcance do objetivo geral, fez-se necessário um trabalho árduo e contínuo com os alunos, para que todos os textos e contextos oriundos da aplicação do programa pudessem ser analisados e avaliados na abordagem da contribuição ao estímulo da participação, exercício da cidadania e desenvolvimento do pensamento crítico, o que em todos os aspectos foram alcançados, comprovado nas falas dos alunos e no decorrer da pesquisa.

As experiências de educação fiscal no Brasil vêm se difundindo cada vez mais, a perspectiva é que ocorram maiores avanços, propiciando a integração da sociedade ao controle social e transparência social da gestão pública.

Baseado no sucesso do programa aplicado em uma escola estadual, considerando a participação e esforço dos alunos, a elaboração de uma cartilha que orienta os trabalhos a serem realizados e a análise dos resultados, fundamentado na ideia de que as fases finais são usadas para aprimorar os resultados das fases anteriores, o próximo passo é a inserção do programa Efin ás escolas municipais para maior abrangência de estudantes e transmissão de conhecimento que contribuem para formação de cidadãos cônscios e mais ativos na busca de melhorias para a cidade de Cáceres - MT.

A pesquisa é de fundamental relevância para a sociedade, explicada nas próprias falas da comunidade ao avaliar a importância que a feira teve como meio de disseminação de conhecimento, transmitindo informações de caráter social e de grande utilização no cotidiano. Para a academia a pesquisa eleva o conceito do curso de ciências contábeis ao elaborar um projeto social, com a participação de alunos de uma escola estadual e engrandece o meio científico com iniciativas de pesquisas experimentais que contribuem diretamente para diminuir a distância entre acadêmico e sociedade.

Dentro do contexto relevância social a pesquisa se destaca como instrumento de utilização nas diversas esferas do governo (Federal, Estadual e Municipal), propiciando o conhecimento e a inserção da sociedade nas decisões a serem tomadas na gestão pública, contribuindo para uma melhor relação da gestão pública para com a sociedade.

Sugere-se a realização de estudos futuros para analisar o perfil socioeconômico e a influência deste no nível do conhecimento já obtido bem como a aceitação das diversas abordagens da educação fiscal. 


\section{REFERÊNCIAS}

BARDIN, L. Análise de conteúdo. Lisboa: Edições 70, 2010.

BRASIL, Constituição (1988). Constituição da República Federativa do Brasil. Brasília, DF: Senado Federal, 1988.

CARMO, Josué Geraldo Botura (2008). Conceituando Educação Fiscal. Disponível em: <paginas.terra.com.br/educacao/josue/index\%20169.html>. Acesso em 10 out. de 2012.

Cidadania e educação fiscal. Disponível em:

<http://www.fdr.com.br/educacaofiscal/?target=apresentacao>. Acesso em 07 jul. 2013, $21 \mathrm{~h} 12 \mathrm{~min}$.

CONFAZ- Conselho Nacional de Política Fazendária. Disponível em: <www.fazenda.gov.br/confaz $>$. Acesso em 01 out. de 2012, 23h08min.

EMEDIATO, Carlos E. Análise Social. Vol.XIV, 1978. $2^{\circ}$ Ed. Morais.

ENGEL, Guido Irineu. Disponível em:

$<$ http://www.educaremrevista.ufpr.br/arquivos_16/irineu_engel.pdf $>$.Acesso em: 05 out. $2012,17 \mathrm{~h} 31 \mathrm{~min}$.

ESAF - Escola de Administração Fazendária da Receita Federal, Programa Nacional deEducação Fiscal. Brasília Vol.8 Disponível: em:

<http://www.esaf.fazenda.gov.br/parceiras/educação-fiscal/programa.pdf $>$.Acesso em: 05 out. de 2012, 20:06.

GADOTTI, Moacir. Educação e poder: interpretação à pedagogia do conflito. 14. ed. São Paulo: Cortez, 2005.

GALVÃO, Raimundo Marcelo Mercês. A Educação Fiscal como um Exercício da

Cidadania / Auditor Fiscal Raimundo Marcelo Mercês Galvão. - Rio de Janeiro: ESG, 2011.

GIL, Antonio Carlos. MÉTODOS E TÉCNICAS DE PESQUISA SOCIAL. 5.ed.São Paulo:Atlas,2007.

GRAU, NuriaCunill. KLIKSBERG, Bernardo. SZEREMETA, Jerzy. FEDOZZI, Luciano. ECHEVERRÍA, Corina. Gestão Pública e Participação. Fundação Luís Eduardo Guimarães. 2005.

LANGONI, Carlos Geraldo. (2005), Distribuição de Renda e Desenvolvimento Econômico no Brasil. $3^{\text {a }}$. ed., Rio de Janeiro, Editora FGV.

Lei n ${ }^{\circ} 9.394$, de 20 de dezembro de 1996. Estabelece as diretrizes e bases da educação nacional. Diário Oficial [da] República Federativa do Brasil, Brasília, 23 dez. 1996. 
LIMA, Aldo José Rodrigues. Políticas Educacionais e Ensino Médio da Literatura brasileira. Dissertação de Mestrado. Recife Universidade Federal de Pernambuco. Centro de Educação.2008.

MAANEN, Jonh, Van. Reclaiming Qualitative methods for organizational research : a preface, in administrative Science Quarterly, Vol.24, no . 4, December 1979.

MELlO, Giomar ao de. Cidadania e Competitividade. 8ª ed. São Paulo. 2000.

MINAYO, M.C.S. O desafio do conhecimento: 11a ed. SãoPaulo, HUCITEC, 2008.

MINISTÉRIO DA FAZENDA. Secretaria da Receita Federal. Programa Nacional de Educação Fiscal. Disponível em

<http://www.receita.fazenda.gov.br/TextConcat/Default.asp?Pos=5\&Div=EducaFiscal > Acesso em 07 out. de 2012, 20:12.

MORAES, R. Análise de conteúdo. Revista Educação, Porto Alegre, 1999.

PNEF. Educação fiscal no contexto social. Programa Nacional de Educação Fiscal. Caderno 01. 4 . ed. Brasília: Ministério da Fazenda, 2009.

PORTINHO, Luiz Cláudio. A Democracia Participativa Brasileira. In: “A priori”, internet. Disponível em

<http://www.apriori.com.br/artigos/democracia_participativa_brasileira.shtml >. Acesso em 27 abr. de 2012, 10h34min.

Qual é o sonho dos Brasileiros? Disponível em:

http://pesquisa.osonhobrasileiro.com.br/indexi2.php?id=1101.Acesso em:05 de jul. $2013,22 \mathrm{~h} 49 \mathrm{~min}$.

QUEIROZ, Tania Lucia de Araujo. CAVALCANTE,Patrícia Smith. As contribuições do software atlas ti para a análise de relatos de experiência escritos. $\mathrm{X}$ Congresso Nacional de Educação - EDUCERE. 2011.

SILVA. Jose Francisco Da. A educação para a cidadania fiscal [manuscrito] : ações do Programa Nacional de Educação Fiscal-PNEF no ensino fundamental e médio / Jose Francisco da Silva. 2011. 